\title{
RETRIVAL BAHASA \\ PADA ANAK BERKEBUTUHAN KHUSUS USIA 8 TAHUN (STUDI KASUS)
}

\author{
Vrestanti Novalia Santosa \\ IKIP Budi Utomo Malang \\ vrestantinov@gmail.com
}

\begin{abstract}
Abstrak
Penelitian retrival bahasa pada anak berkebutuhan khusus masih jarang ditemukan. Banyak peneliti bahasa kurang berminat meneliti anak berkebutuhan khusus, selain itu proses pengambilan data membutuhkan waktu yang cukup lama dan berulang sampai data yang ditemukan mengalami kesamaan atau titik jenuh, ini berarti proses pengambilan data tertentu dinyatakan cukup dan selesai. Tujuan penelitian ini (1) mendeskripsikan bentuk fona, kata, dan kalimat yang mampu dikeluarkan anak berkebutuhan khusus usia 8 tahun, (2) mendeskripsikan makna kalimat berdasarkan konteks yang mampu dikeluarkan anak berkebutuhan khusus usia 8 tahun. Pendekatan yang digunakan kualitatif-deskriptif dan merupakan jenis penelitian studi kasus. Teknik pengumpulan data menggunakan (1) teknik observasi partisipasi, (2) rekam, (3) catat, (4) pemancingan, dan (5) dokumentasi. Dapat disimpulkan bahwa (1) bentuk fona vokal yang mampu dikeluarkan subjek penelitian diketahui dapat menempati semua posisi dalam satu satuan ujaran, tidak semua fona konsonan mampu dikeluarkan. (2) bentuk kata, jenis kebutuhan khusus berpengaruh terhadap kekompleksan kata yang mampu dikeluarkan subjek penelitian. Semakin sedikit kata yang mampu dikeluarkan semakin kompleks jenis kebutuhan khusus subjek penelitian. (3) bentuk kalimat, variasi kalimat yang dihasilkan adalah jenis kalimat sederhana. (4) makna kalimat sesuai konteksnya, jenis kalimat tergolong simpleks, terdapat perbedaan signifikan dengan kalimat yang seharusnya dihasilkan oleh anak dengan perkembangan normal seusianya.
\end{abstract}

Kata kunci: retrival bahasa, anak berkebutuhan khusus 


\section{PENDAHULUAN}

Selama ini penelitian mengenai retrival bahasa pada anak berkebutuhan khusus masih jarang ditemukan. Pemahaman masyarakat mengenai retrival bahasa pada anak berkebutuhan khusus masih kurang. Terlebih lagi, masyarakat memandang sebelah mata terhadap anak yang memiliki kebutuhan khusus. Kondisi seperti ini menimbulkan dorongan adanya jenis penelitian mengenai retrival bahasa pada anak berkebutuhan khusus usia 8 tahun. Tujuan penelitian ini adalah (1) mendeskripsikan bentuk fona, kata, dan kalimat yang mampu dikeluarkan kembali anak berkebutuhan khusus usia 8 tahun, (2) mendeskripsikan makna kalimat berdasarkan konteks yang dikeluarkan kembali anak berkebutuhan khusus usia 8 tahun.

\section{METODE PENELITIAN}

Dalam penelitian ini menggunakan pendekatan kualitatifdeskriptif, dan merupakan jenis penelitian studi kasus. Jenis penelitian studi kasus merupakan penelitian yang tepat apabila rumusan masalah yang dipecahkan adalah berkenaan dengan pertanyaan "bagaimana dan mengapa", apabila peneliti hanya memiliki sedikit peluang untuk mengontrol peristiwaperistiwa yang diteliti, dan apabila fokus penelitiannya terletak pada fenomena kontemporer (masa kini) di dalam konteks kehidupan nyata. Penelitian studi kasus dibedakan menjadi tiga tipe, yaitu studi kasus eksplanatoris, eksploratoris, dan deskripstif (Yin, 1987:1). Subjek penelitian ini adalah seorang anak dengan kebutuhan khusus usia 8 tahun. Dalam hal ini diambil subjek penelitian anak dengan kebutuhan khusus secara acak di suatu sekolah inklusi.

Subjek penelitian diambil berdasarkan pertimbangan bahwa subjek tersebut tergolong anak berebutuhan khusus dengan usia 8 tahun yang memiliki karakteristik sebagai berikut. (1) Adanya ketidakseimbangan antara sistem otak dengan penalaran dan sistem memori yang memberitahu otak apa yang paling penting untuk pemberitahuan atau bagaimana mengaturnya tematis. Dalam hal ini, tidak ditemukan kesinambungan 
antara apa yang dipikirkan dengan apa yang dilakukannya. (2) Anakanak dengan kebutuhan khusus yang memiliki memori kerja yang kurang sesuai untuk informasi spasial, atau mengingat dari waktu ke waktu di mana sesuatu itu berada setelah keluar dari pandangan. Meskipun memori bekerja untuk informasi verbal baik-baik saja, hasil keluaran bahasa terhadap urutan spasial dengan mudah dibedakan antara anak-anak normal dengan anak-anak yang memiliki kebutuhan khusus. Memori kerja spasial tergantung pada daerah tertentu dari korteks frontal yang diketahui disfungsional.

(3) Pengamatan dari beberapa ciri menurut Sunu (2012:16-18) sebagai berikut. (a) Aloof . Subjek penelitian berusaha menarik diri dari kontak sosial, dan cenderung untuk menyendiri di pojok. (b) Passive. Subjek penelitian tidak berusaha mengadakan kontak sosial melainkan hanya menerima saja. (c) Active but odd. Subjek penelitian melakukan pendekatan namun hanya bersifat satu sisi yang bersifat repetitif dan aneh. (4) Kualifikasi kelas subjek penelitian didasarkan atas usia dan tipe kebutuhan khusus. Psikolog sekolah sebelumnya melakukan tes terlebih dahulu terhadap kemampuan intelektual anak sebelum penempatan di kelas sesuai dengan rancangan program yang tepat untuk anak dengan kebutuhan khusus di sekolah. Subjek penelitian mengalami gangguan disintergratif masa kanak (childhood disintegrative disorder) merupakan gangguan yang melibatkan hilangnya keterampilan yang telah dikuasai anak setelah satu periode perkembangan normal pada tahun pertama. Gangguan ini biasa muncul pada anak laki-laki. Perkembangan normal anak hanya terjadi pada tahun pertama, setelah itu secara signifikan keterampilan yang telah dimiiki seperti pemahaman, penggunaan bahasa, dan yang lainnya menghilang. Selain itu juga terjadi keabnormalan fungsi yang tampak pada gangguan komunikasi, serta minat dan aktivitas yang sempit. Subjek penelitian juga mengalami sindrom asperger (asperger's syndrome) adalah bentuk yang lebih ringan dari gangguan perkembangan pervasif. Ditunjukkan dengan penarikan diri dari interaksi sosial serta perilaku stereotip, namun tanpa disertai keterlambatan yang 
signifikan pada aspek bahasa dan kognitif. Asparger mirip dengan autisme infantil dalam hal interaksi sosial yang kurang.

Dalam penelitian ini terdapat kehadiran peneliti. Peneliti studi kasus memusatkan perhatian pada aspek konsep atau pendesainan dan penyelenggaraan pada penelitiannya (Yin, 1987:1). Kehadiran peneliti sangat menentukan kualitas hasil penelitiannya. Kehadiran peneliti dalam hal ini sebagai pengumpul data, pemberi stimulus atau pancingan agar subjek penelitian mengeluarkan ujaran (jika diperlukan), dan penentu banyaknya data yang diperoleh saat penelitian. Selama pengumpulan data, hanya peneliti yang peka yang dapat memanfaatkan peluang-peluang tak terduga yang ditemukan, cukup hatihati dalam menghadapi prosedur yang bias. Seorang peneliti studi kasus harus memiliki keterampilan yang cukup guna melaksanakan pengumpulan data. Hal-hal yang harus dimiliki seorang peneliti studi kasus, misalnya daftar pertanyaan, pendengaran yang baik, penyesuaian diri dan fleksibilitas yang baik, memegang teguh isu atau target yang diteliti, dan mampu mengurangi bias.

Adapun instrumen penelitian yang digunakan dalam penelitian ini adalah (1) lembar pemancingan, (2) alat identifikasi anak berkebutuhan khusus, (3) alat rekam (camera digital). Penelitian ini menggunakan teknik pengumpulan data antara lain: (1) teknik observasi partisipasi (pengamatan), (2) teknik rekam, (3) teknik catat, (4) teknik pemancingan, dan (5) teknik dokumentasi. Berdasarkan urutan permasalahan yang telah ditetapkan, peneliti melakukan beberapa tahap berikut dalam analisis data.

Pengidentifikasian data,

penglasifikasian data,

penganalisisan data, (4) penyimpulan data.

\section{HASIL DAN PEMBAHASAN}

Sejalan dengan tujuan penelitian, hasil penelitian sebagai berikut. (1) pada subjek penelitian fona vokal /i/, /u/, /e/, / /, / /, /o/, /J/, /a/ dapat menempati semua posisi pada satu satuan ujaran. (2) Subjek penelitian sudah mampu menyimpan dan memanggil fona konsonan /t/, $/ \mathrm{k} /, / \mathrm{s} /, / 1 /, / \mathrm{m} /, / \mathrm{n} /$, dan $/ \mathrm{y} /$ terdapat 
pada semua posisi, yaitu posisi depan, tengah, dan belakang. (3) Berdasarkan kelas kata dapat diketahui subjek penelitian mengenal jenis-jenis kata, dengan pengklasifikasian sebagai berikut. Kata yang mampu dikeluarkan kembali dapat diklasifikasikan ke dalam kelas kata, yaitu nomina, verba, adjektiva, terdapat pada kata adverbia, pronomina, numeralia:angka kardinal, kata tanya, kata tugas: kata sandang. Dari hasil analisis frekuensi kemunculan kelas kata subjek penelitian, diketahui bahwa kelas kata nomina frekuensi kemunculannya lebih tinggi dibanding kelas kata verba, adjektiva, adverbia, pronomina, numeralia, kata tanya, kata tugas. (4) Pada subjek penelitian, variasi kalimat yang dihasilkannya termasuk ke dalam jenis kalimat sederhana, hanya ditemukan lima jenis kalimat, yaitu kalimat berita (deklaratif), kalimat perintah (imperatif), kalimat tanya (interogatif), kalimat inversi, dan kalimat ingkar.

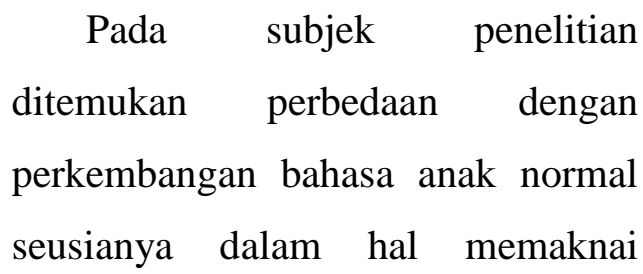

kalimat berdasarkan konteksnya, yaitu pada subjek penelitian kalimat yang mampu dikeluarkan kembali masih simpleks Kalimat dengan struktur sederhana yang dikeluarkan subjek penelitian kurang dapat dipahami secara jelas antara kalimat yang dipanggil dengan konteks saat itu. Berbeda dengan anak normal seusianya, kalimat dengan struktur yang bervariasi dapat lebih mudah dianalisis dan kesesuaian antara kalimat yang dikeluarkan dengan konteksnya lebih dipahami secara jelas.

\section{SIMPULAN}

Dari hasil penelitian dapat disimpulkan bahwa (1) berdasarkan bentuk fona vokal yang mampu dikeluarkan kembali oleh subjek penelitian dapat menempati semua posisi dalam satu satuan ujaran, tidak semua fona konsonan mampu dipanggil subjek penelitian, yakni pada fona konsonan /z/, /x/, dan /y/. (2) Berdasarkan bentuk kata, anak berkebutuhan khusus menghasilkan kata yang lebih sedikit daripada anak dengan perkembangan normal. Tingkat kebutuhan khusus berpengaruh terhadap kekompleksan 
kata yang dikeluarkan kembali oleh subjek penelitian. Semakin sedikit kata yang dipanggil semakin tinggi tingkat kebutuhan khusus seorang subjek. (3) Berdasarkan bentuk kalimat, pada subjek penelitian, variasi kalimat yang dihasilkannya termasuk ke dalam jenis kalimat sederhana. (4) Berdasarkan makna kalimat sesuai konteksnya, pada subjek penelitian ditemukan perbedaan dalam hal memaknai kalimat berdasarkan konteksnya, yaitu pada subjek penelitian, kalimat yang mampu dikeluarkan kembali masih simpleks dibanding kalimat yang mampu dikeluarkan kembali anak dengan perkembangan normal seusianya sehingga saat dianalisis makna kalimat berdasarkan konteksnya terdapat perbedaan yang signifikan.

\section{SARAN}

Adapun saran-saran penelitian ini adalah sebagai berikut. (1) Bagi orang tua, Penelitian ini diharapkan dapat memberikan masukan bagi orang tua yang memiliki anak yang memiliki kebutuhan khusus maupun yang memiliki anak normal seusianya agar lebih memperhatikan dan memahami karakter buah hatinya. Pada dasarnya orang tua mempunyai pengaruh besar terhadap perkembangan bahasa seorang anak karena orang tua adalah sumber bahasa utama bagi anak. Langkah yang dapat dilakukan orang tua misalnya mengenalkan hal baru kepada anaknya, setiap hal yang dilakukan anak terkonsep dengan baik, disediakan media atau alat di rumah sebagai penstimulasi kosakata yang baru sebagai bahan pembelajaran atau pengenalan terhadap sesuatu yang baru. Misalnya menyediakan beberapa macam mainan yang berbeda jenisnya, menyediakan gambargambar berwarna sesuai yang ada dalam kehidupannya, serta mengenalkan hal-hal baru dengan langsung mempraktikannya. Selain itu, orang tua bisa melakukan kegiatan wisata terjadwal, misalnya mengunjungi tempat wisata kebun binatang. Selain dapat membuat buah hati relaks, dapat digunakan sebagai tempat pembelajaran mengenal binatang, sehingga kemampuan mengeluarkan kembali bahasa yang dimiliki anak semakin meningkat, baik dari bentuk fona, kata, maupun 
kalimat yang dihasilkan. (2) Bagi peneliti lain. Penelitian ini diharapkan dapat memberikan saran dan masukan yang sekiranya dapat digunakan sebagai bahan pertimbangan guna perbaikan penelitian berikutnya yang terkait dengan penelitian mengenai retrival bahasa berbentuk fona, kata, dan kalimat serta makna kalimat berdasarkan konteksnya karena selama ini penelitian mengenai retrival bahasa pada anak berkebutuhan khusus masih jarang ditemukan. Berdasarkan hasil analisis pada penelitian ini, terdapat fona, kata, dan kalimat yang belum mampu dipanggil subjek penelitian, peneliti lain dapat menggunakan teknik pemancingan ketika pengambilan data pada fona, kata, dan kalimat. Teknik pemancingan ini bisa menggunakan bahan pemancingan berupa gambar yang lebih bervariasi, memanfaatkan benda-benda yang ada di sekitar subjek penelitian, dan mengenalkan sesuatu yang baru kepada subjek penelitian agar fona, kata, dan kalimat yang dihasilkan mengalami peningkatan. (3) Bagi tutor anak berkebutuhan khusus. Penelitian ini diharapkan dapat memberikan saran dan masukan yang dapat digunakan sebagai bahan pertimbangan bagi tutor anak berkebutuhan khusus mengenai kemampuan mengeluarkan kembali bahasa pada para peserta didiknya, sehingga tutor anak berkebutuhan khusus lebih mudah memahami karakter peserta didiknya. Berdasarkan hasil penelitian yang telah dilaksanakan, bentuk fona yang belum mampu dikeluarkan kembali oleh subjek penelitian seperti fona vokal /i/ tinggi-depan tertutup, fona vokal /u/ tinggi-belakang, fona konsonan /d/ plosif-apikoalveolar bersuara di posisi depan dan tengah, fona konsonan /r/ tril-alveolar, fona konsonan / $\tilde{n} /$ nasal-laminopalatal dan /y/ nasal-dorsovelar pada posisi depan, fona konsonan /h/ frikatiflaringal bersuara pada posisi tengah, dan fona konsonan / $f$ / frikatif-palatal dapat diperbaiki dengan melaksanakan pembiasaan melalui bantuan pemancingan berupa latihan vokal secara berulang, menggunakan media gambar atau benda yang dapat mendorong anak mengeluarkan ujaran yang sebelumnya belum terbiasa dan belum mampu diujarkan 
secara tepat. Berdasarkan hasil penelitian mengenai bentuk kata dan kalimat yang belum mampu dipanggil subjek penelitian, dapat disarankan dalam pembelajaran seorang tutor dapat mempersiapkan bahan atau alat yang dapat menstimulasi peserta didiknya, misalnya melalui bantuan gambar atau benda yang tentunya dapat menambah kosakata baru dan kalimat yang lebih kompleks pada peserta didiknya. Adapun contoh yang bisa dilakukan, misalnya mengadakan pembelajaran makan buah bersama, di dalam pelaksanaannya telah disiapkan bermacam-macam jenis buah sehingga selain mengetahui bagaimana cara makan yang baik, tutor anak berkebutuhan khusus mengetahui ujaran apa saja yang muncul selama proses makan buah, selain itu peserta didik mengetahui jenis-jenis buah yang dikonsumsinya, sehingga kelas kata dan bentuk kalimat yang dimiliki peserta didik lebih bervariasi tidak hanya terbatas pada kata benda, kata dasar, dan kalimat berita saja. Saran yang bisa dijadikan bahan pertimbangan tutor mengenai makna kalimat berdasarkan konteksnya yaitu misalnya mengadakan kelas bina diri, memberikan pembelajaran pada peserta didik untuk melakukan kegiatannya sendiri menyesuaikan dengan konteksnya saat itu. Dengan hal seperti itu diharapkan peserta didik yang awalnya hanya mengenal kehidupan yang ada pada dirinya dapat mulai belajar mengenal kehidupan atau aktivitas di luar dirinya, sehingga ujaran yang dihasilkan dapat dimaknai tepat sesuai konteksnya. (4) Bagi penyusun bahan ajar anak berkebutuhan khusus. Penelitian ini dapat dijadikan masukan dan bahan pertimbangan ketika menyusun bahan ajar anak berkebutuhan khusus. Dari hasil penelitian ini, penyusun bahan ajar dapat menambahkan lembar pemancingan berupa peta bagan vokal dan konsonan dalam bahan ajarnya sebagai media guru dalam kegiatan pembelajaran di kelas sehingga memudahkan guru dalam mengamati pemerolehan ujaran peserta didiknya. Penyusun bahan ajar juga dapat menyusun materi-materi sesuai kurikulum dengan menekankan 
bagian tersebut sesuai dengan konteksnya.

\section{DAFTAR RUJUKAN}

Arifuddin. 2010.

Neuropsikolinguistik. Jakarta: Rajawali Pers.

Bellugi, Ursula and Brown, Roger. 1964. The Acquisition of Language. Chicago: The University of Chicago Press.

Bruner, Jerome S.; et al. 1966. Studies in Cognitive Growth: A Collaboration at the Center for Cognitive Studies. USA: John Wiley \& Sons, Inc.

Chaer, Abdul. 2009. Fonologi Bahasa Indonesia. Jakarta: Rineka Cipta.

Chaer, Abdul. 2009. Psikolinguistik: Kajian Teoretik. Jakarta: Rineka Cipta.

Danim, Sudarwan. 2002. Menjadi Peneliti kualitatif. Bandung: Pustaka Setia.

Dardjowidjojo, Soenjono. 2012. Psikolinguistik: Pengantar Pemahaman Bahasa Manusia. Jakarta: Yayasan Pustaka Obor Indonesia.

Davidson, Gerald C. and John, M. Neale. 2000. Abnormal Psychology. USA: John Wiley and son, Inc.

Depdikbud. 1989. Kamus Besar Bahasa Indonesia. Jakarta: Balai Pustaka.

Dinas Pendidikan Propinsi Banten. 2002. Alat Identifikasi Anak Berkebutuhan Khusus (AI $A B K)$.

Fuller, Geraint. 2008. Panduan Praktis Pemeriksaan
Neurologis. Jakarta: Buku Kedokteran EGC.

Kridalaksana, Harimurti. 1993. Kamus Linguistik. Jakarta: Gramedia Pustaka Utama.

Lauder, Alan F. dan Kushartanti. 2005. Pesona Bahasa Langkah Awal Memahami Linguistik. Jakarta: Gramedia Pustaka Utama.

Lumbantobing, S.M. 2010. Neurologi Klinik:

Pemeriksaan Fisik dan Mental. Jakarta: FKUI.

McGaugh, James L. 1973. Learning and Memory: An Introduction. California: Albion Publishing Company.

Mar'at, Samsunuwiyati. 2009. Psikolinguistik: $\quad$ Suatu Pengantar. Bandung: Refika Aditama.

Moleong, Lexy J. 2002. Metodologi Penelitian Kualitatif. Bandung: Remaja Rosdakarya.

Muslich, Masnur. 2011. Fonologi Bahasa Indonesia. Jakarta: Bumi Aksara.

Peeters, Theo. 2012. Panduan Autisme Terlengkap. Jakarta: Dian Rakyat.

Purwo, Bambang Kaswanti. 1990. Perkembangan Bahasa Anak: Dari Lahir sampai Masa Prasekolah. Makalah disajikan dalam PELLBA 3 (027430), Yogyakarta: Kanisius, hlm. 91-118.

Rachmawati, Niza. 2009. Pola Berbicara dan Proses Fonologis Bahasa Indonesia pada Tuturan Anak Autis (Studi kasus pada Ifan dan Yessica). Skripsi tidak diterbitkan. Surabaya: FBS Unesa. 
Rahmawati, Neny. 2004. Kajian Fonologis Ekspresi Berbicara Penderita Penyakit Disartria: Studi kasus pada Ratih Yuniar dan Dana Rosilawati. Skripsi tidak diterbitkan. Surabaya: FBS Unesa.

Samarin, William J. Tanpa Tahun. Ilmu Bahasa Lapangan. Terjemahan Badudu, J.S.. 1988. Yogyakarta: Kanisius.

Santosa, Vrestanti Novalia. 2011. Gangguan Berbahasa Anak Berkebutuhan Khusus Jenis Afasia Usia 7 Tahun (Studi Kasus pada Feemas). Skripsi tidak diterbitkan. Surabaya: FBS Unesa.

Santosa, Vrestanti Novalia. 2015. Daya Panggil Bahasa Berbentuk Fona, Kata, dan Kalimat pada Anak Autis Usia 9 Tahun. Tesis tidak diterbitkan. Malang: Pascasarjana Universitas Negeri Malang.

Sastra, Gusdi. 2005. Ekspresi Verbal Penderita Strok Penutur Bahasa Minangkabau: Suatu Analisis Neurolinguistik. Artikel disajikan dalam Kongres Linguistik Nasional XI MLI, Padang, Sumatra Barat, 18-21 Juli, hlm. 104107.

Sidharta, Priguna. 1989. Segi Medis Gangguan Ekspresi Verbal. Makalah disajikan dalam PELLBA 2 (027421), Yogyakarta: Kanisius, hlm. 163-180.

Sidiarto, Lily. 1991. Berbagai Gangguan Berbahasa Pada Anak. Makalah disajikan dalam PELLBA 4 (027432),
Yogyakarta: Kanisius, hlm. 133-148.

Sunu, Christopher. 2012. Unlocking Autism. Jakarta: Lintangterbit.

Tarigan, Henry Guntur. 1985. Psikolinguistik. Bandung: Angkasa.

Wijana, Dewa Putu. 1996. Dasardasar Pragmatik. Yogyakarta: Andi Offset.

Yin, Robert K. 1987. Studi Kasus: Desain dan Metode. Terjemahan Mudzakir, M. Djauzi. 2014. Jakarta: Rajawali Pers.

Yulianto, Bambang dan Tirtawijaya, Totong. 1989. Fonologi. Surabaya: IKIP Surabaya. 